\title{
Switch from oral anticoagulants to parenteral heparin in SARS-CoV-2 hospitalized patients: comment
}

\author{
Attilio Allione $^{1} \cdot$ Jacopo Davide Giamello ${ }^{2}$ (D) $\cdot$ Giulia Paglietta $^{2} \cdot$ Sara Bernardi $^{1} \cdot$ Giulia Cavalot $^{1}$
}

Received: 5 May 2020 / Accepted: 8 May 2020 / Published online: 21 May 2020

(c) Società Italiana di Medicina Interna (SIMI) 2020

\section{Dear Editor,}

In their point-of-view article "Switch from oral anticoagulants to parenteral heparin in SARS-CoV-2 hospitalized patients", Testa and colleagues supported the early replacement of oral anticoagulant therapy with heparin in patients hospitalized for Coronavirus disease 2019 (COVID-19) with the exception of those with a mechanical heart valve [1].

In this regard, we would like to report our experience; to date, 70 patients with Sars-CoV2-related pneumonia have been admitted to our High Dependency Unit (HDU). Five patients developed pulmonary embolism (PE) during hospitalization, four of them while on prophylactic heparin, and one despite treated with oral anticoagulation with warfarin, since he was carrying a mechanical prosthetic heart valve. Unsurprisingly, prophylactic doses of heparin did not prevent the occurrence of VTE, whereas we were puzzled that the patient with the mechanical heart valve developed PE despite INR values in the therapeutic range, or even above.

We retrospectively analyzed these patients' laboratory tests. All of them showed an initial increase in inflammatory markers such as $\mathrm{C}$ reactive protein (CRP), lactate dehydrogenase (LDH), and interleukin-6 (IL6), if available, with a subsequent marked increase in d-dimer values followed by the diagnosis of pulmonary embolism. Our hypothesis, in line with the available literature [2], is that thrombotic events that occur in these patients may be closely related to the inflammatory phase of the disease known as "cytokine storm" and somehow predicted by the rise in inflammatory markers. During this cytokine storm, IL-6 in particular is known to be elevated; we speculate that it could play a role

Jacopo Davide Giamello

jacopo.giamello@gmail.com

1 Department of Emergency Medicine, Santa Croce and Carle Hospital, Cuneo, Italy

2 School of Emergency Medicine, University of Turin, Turin, Italy in the pro-coagulative state of COVID-19 patients through its effect on the activation of the plasminogen activator inhibitor (PAI), which indirectly inhibits plasminogen [3]. PAI is a pro-thrombotic factor and it is conceivable that IL-6 and PAI may be one of the links connecting COVID-19 to thrombosis.

Given these considerations, it has been hypothesized that the efficacy of heparin in these patients may be multi-factorial, including a possible anti-inflammatory action alongside the known anticoagulant one [4]. In this context, our observation of a case of PE despite anticoagulant therapy with warfarin and INR in therapeutic range could place in favor of a heparin therapy switch also in the category of patients considered to be the greatest thrombotic risk such as mechanical heart valve carriers.

In the presence of COVID-19, the exclusive use of common coagulation tests ( such as INR and aPTT) constitutes a limit in the interpretation of the coagulation status of these patients. It is known that INR and aPTT reflect the procoagulant arm of the coagulative balance and do not provide information regarding fibrinolytic activity. Under these circumstances, the study of the viscoelastic properties of the clot based on thromboelastography (TEG) might help clinicians to better evaluate the patient's coagulation status [5]. We suggest that TEG could guide anticoagulant therapy in critically ill patients with COVID-19 and mechanical heart valves, when coagulation times (i.e., INR and aPTT) may prove unreliable.

In this unpredictable balance, patients on VKA therapy for mechanical heart valves represent an additional and unknown challenge urgently necessitating good-quality evidence. Viscoelastic testing (thromboelastometry) may have a role in guiding the therapeutic strategy (e.g., switching from VKA to heparin in case of documented hypercoagulability) alongside a close monitoring of fibrinogen, d-dimer, CRP, and $\mathrm{LDH}$, to remain in balance while walking on the tightrope of coagulation. 


\section{Compliance with ethical standards}

Conflict of interest The authors declare that they have no conflict of interest.

Statement of human and animal rights All procedures performed in study involving human participants were in accordance with the ethical standard of the institutional research committee and with the 1964 Helsinki declaration and is its later amendments or comparable ethical standards. This article does not contain any study with animals performed by any of the authors.

Informed consent Informed consent for publication has been obtained from cited patients.

\section{References}

1. Testa S, Paoletti O, Giorgi-Pierfranceschi M, Pan A (2020) Switch from oral anticoagulants to parenteral heparin in SARS-CoV-2 hospitalized patients. Intern Emerg Med. https://doi.org/10.1007/ s11739-020-02331-1
2. Jose RJ, Manuel A (2020) COVID-19 cytokine storm: the interplay between inflammation and coagulation [published online ahead of print, 2020 Apr 27]. Lancet Respir Med. https://doi. org/10.1016/S2213-2600(20)30216-2

3. Dong J, Fujii S, Imagawa $S$ et al (2007) IL-1 and IL-6 induce hepatocyte plasminogen activator inhibitor-1 expression through independent signaling pathways converging on C/EBPdelta. Am J Physiol Cell Physiol 292(1):C209-C215. https://doi.org/10.1152/ ajpcell.00157.2006

4. Li X, Ma X (2017) The role of heparin in sepsis: much more than just an anticoagulant. Br J Haematol 179(3):389-398. https://doi. org/10.1111/bjh.14885

5. Spiezia L, Boscolo A, Poletto F et al (2020) COVID-19-related severe hypercoagulability in patients admitted to intensive care unit for acute respiratory failure [published online ahead of print, 2020 Apr 21]. Thromb Haemost. https://doi. org/10.1055/s-0040-1710018

Publisher's Note Springer Nature remains neutral with regard to jurisdictional claims in published maps and institutional affiliations. 